Cormac McGrath, KAROLINSKA INSTITUTET, cormac.mcgrath@ki.se • Linda Barman, THE ROYAL INSTITUTE OF TECHNOLOGY \& KAROLINSKA INSTITUTET, lbarman@kth.se Terese Stenfors-Hayes, KAROLINSKA INSTITUTET, terese.stenfors-hayes@ki.se Torgny Roxå, LUND UNIVERSITY, torgny.roxa@lth.lu.se Charlotte Silén, KAROLINSKA INSTITUTET, charlotte.silen@ki.se Klara Bolander Laksov, STOCKHOLM UNIVERSITY \& KAROLINSKA INSTITUTET, klara.bolander.laksov@edu.su.se

\title{
The Ebb and Flow of Educational Change: Change Agents as Negotiators of Change
}

\begin{abstract}
In this paper, we are concerned with how change agents go about and experience change implementation in higher education. We identified change agents and interviewed them about how they implement change. Empirical data was analysed using a theoretical framework of change. The findings suggest that change in the university is enacted through a process of negotiation. The findings of this study may offer academic developers, pedagogical leaders, and change agents insight into the complex nature of the change process and inform change agents as to the complex nature and importance of their role.
\end{abstract}

\section{KEYWORDS}

change agents, capacity building, Change Process Prescriptions (CPP), resistance, negotiation

\section{INTRODUCTION}

Universities tend to adopt distributed or shared leadership models (Bolden, Petrov, \& Gosling, 2009) where many leaders in higher education (HE) adopt their positions out of a sense of duty (Askling \& Stensaker, 1999), evoking a collegial culture towards leadership as opposed to a managerial culture (Bergquist, 1992). A consequence of adopting collegial approaches to leadership is that the appointed leaders' leadership skills are often acquired through a process of trial and error. For the most part, collegial leaders lack formal training (Newton, 2003). Often leaders in HE are academics that hold multiple roles within the university as teachers and researchers (Askling \& Stensaker, 1999). One of the roles academic collegial leaders often hold may be the role of change agent. This raises concerns as to how HE bodies organise and implement change initiatives, and illustrates a dilemma whereby the change agents are experts in one regard-in relation to their discipline-but are often amateurs in regard to their position as educational change agents. Coupled with this, change related to educational matters in HE occurs in a dynamic and complex setting. In this paper we pose two research questions: how do change agents go about implementing change? Secondly, how can we understand tensions between these change agents' experiences of change and systematic models of change? ${ }^{1}$ 
By illuminating change agents' strategies of change and the challenges that arise when working with change, we may better understand how change can be brought about in higher education and how it can inform an emerging theory of change agency in higher education (Trowler, Fanghanel, \& Wareham, 2005). Trowler, Fanghanel, and Wareham (2005) identify the need to establish a robust theory of change and an associated set of policies at the meso or departmental level. This paper reports on the experiences and reflections of academic collegial leaders who were identified as change agents in a research-intensive higher education institution. In this study, a collegial leader is someone who has shown an interest in educational matters and is assigned time to bring about educational initiatives within the department. The collegial leaders form a larger group $(n=25)$ across the university and occasionally meet informally to share experiences. In line with research into knowledge-intense organisations (Askling \& Stensaker, 1999; Newton, 2003; Bolden, Petrov, \& Gosling, 2009), collegial leaders with a mandate to effect and support change act as a conduit between teaching faculty and institutional leadership. This paper may therefore serve as a reference point for how collegial leaders could organise across the campus. Consequently, the purpose of this paper is to develop an understanding of the processes that occur when change takes place. In doing so, the paper aims to help significant actors, including leadership figures and academic developers, to operate in a more considered and better-informed way when working with change.

Change can, of course, be many things. Recently Trowler, Hopkinson, and Comerford Boyes (2013) identified a number of salient types of change initiatives:

1. Small-scale bottom-up initiatives or projects led and driven by a small number of enthusiastic and committed individuals.

2. Larger-scale organisational (top-down) initiatives involving wider institutional support, staffing, and/or resources.

3. Integrated whole-institutional (top-down) initiatives with significant institutional support linking multiple sustainability activities, often with an added dimension involving wider cultural change.

In this paper we are mostly concerned with the first and second categories of change, as they constitute change in the meso level of the organisation. Our research group is also concerned with the third form of change, which is being studied simultaneously and will be addressed elsewhere (Barman, Silén, \& Bolander Laksov, 2014; Barman, Bolander Laksov, \& Silén, 2014). In order to explore our research questions, stories of change were collected, analysed, and mapped into a conceptual framework (Change Process Prescriptions, CPP) (Meyer \& Stensaker, 2006). The CPP framework was chosen as it represents a heuristic tool for understanding how change processes may be facilitated in organisations (ibid). It was believed that it may contribute to our understanding of how a robust theory of change at the meso or departmental level could be addressed (Trowler et al., 2005.

\section{THEORETICAL FRAMEWORK \\ Change capacity}

The literature on organisational change suggests that organisations react very differently to calls for change. There is no consensus in the literature as to how change is best implemented (Amis, Slack \& Higgins, 2004). There is, however, consensus that organisations need to build a capacity for dealing with change (Meyer \& Stensaker, 2006) and also that organisations need to embrace change as the normal condition of organisational life (Tsoukas \& Chia, 2002). Meyer and Stensaker (2006) define change capacity in terms of three interconnected capabilities:

a) the capability to maintain daily operations,

b) the capability to implement a single change, and, 
c) the capability to implement subsequent changes.

A challenge for higher education institutions as well as other knowledge-intensive organisations lies in being able to balance these capabilities at the same time (Trowler, 1998; Meyer \& Stensaker, 2006). Furthermore, it is argued that the successful implementation of one particular change initiative may harm subsequent change initiatives (ibid). Consequently, change agents in HE may need to focus on change not as isolated events, but as a series of interrelated changes, and build within the organisation a culture of change whereby change awareness is a conscious part of work (Trowler et al., 2005; Meyer \& Stensaker, 2006; McGrath \& Bolander Laksov, 2014). This is further emphasised in the literature on organisational change where there is a strong emphasis on the notion of becoming an organisation, something that is achieved through evoking common values, beliefs, and habits (Tsoukas \& Chia, 2002). Meyer and Stensaker (2006) argue that for change to be sustainable, a number of Change Process Prescriptions (CPPs) need to be utilised:

- framing - identifying and communicating what is to be done

- participation-allowing the members of the organisation to be involved in planning

- pacing and sequencing - pacing the rate of change

- routinizing and recruiting - recruiting people to take part and routinizing the new elements with on-going operations (ibid).

These prescriptions constitute one approach to change agency that serves more as a heuristic for reflection and less as an instrumental step-by-step checklist approach to change implementation.

\section{Change agents}

The literature on change capacity identifies the role of the change agents as central, and as effective intermediaries in creating operational impetus for improved performance (Dover, 2002). However, change agents may not always understand the degree of involvement that is needed, or the necessary steps required when going from idea to action (Higgs \& Rowland, 2000). In higher education it is not uncommon that colleagues are appointed as collegial leaders with a mandate to act as change agents. Like many others who have adopted their positions due to a sense of responsibility (Askling \& Stensaker, 2002), change agents are frequently put in situations whereby they are implementing changes they themselves have not initiated. In this paper the change agents we identified were collegial leaders; in other words, they were colleagues appointed from within the organisation, without following a formal application process. Furthermore, they had received no formal training in being leaders. In their role as collegial leaders they were expected to act as change agents and impact change initiatives relevant to educational matters. This may have implications for how they perceive their roles. Similar findings were demonstrated recently in a study where program directors and course directors in a higher education institution were found often to perceive themselves as administrators rather than as leaders of change and educational development (Bolander Laksov \& Tomson, 2016). Being a change agent involves finding a balance between implementing top-down policy and adhering to calls for change from within the organisation (Stensaker, 1999).

Change occurs in a dynamic, social environment, full of explicit and implicit tensions, pressure and fatigue (Jones, 2011) between the managed and the managers (Newton, 2003). This has been well documented previously, especially in relation to initiatives designed to improve learning and teaching (Trowler \& Cooper, 2002; Newton, 2003). Change agents act in different communities as discipline experts, researchers, teachers, supervisors, study directors. This study was conducted in a life science and health care-oriented, research-intense institution and so it was not uncommon for the staff to have clinical duties too. 
Caldwell identifies four discourses for agency within organisations: rationalist, contextualist, dispersalist, and constructionist (Caldwell, 2006). The rationalist discourse is characterised by intentional action, rationality and expertise, and a strong belief that human behaviour in organisations is part of a functional system that can be expertly designed and re-designed. The contextualist discourse places the notion of human agency in the context of bounded choices that occur within competing group interests, organisational politics, and power struggles. The dispersalist discourse identifies agency as de-centred or distributed, taking the form of self-organising groups who come together in order to cope with policy change, innovation, etc. The constructionist discourse is loosely characterised by socially constructed worlds of fragmented cultural discourses (Caldwell, 2006, p. 7). Caldwell presents the discourses as theoretical constructs that allow us an insight into the field of organisational development. The four discourses run across a spectrum depicting higher education organisations as being extremely well organised, idealistic, and obedient organisations on one end of the spectrum, to being organisations without a central coherent structure on the other. These different discourses, while primarily representing theoretical constructs, also represent the different ways in which staff and management can perceive how change is conducted. While there is an overlap between the discourses, it is clear that the rationalist discourse is not readily compatible with the dispersalist, and so problems are likely to arise if change agents are unaware of the different points of departure.

The discourses form an important background to this study. In contrast to the theoretical constructs and discourses, change agents also have to cope with existing, real life teaching and learning regimes (TLR) that are often tribal in the nature (Becher \& Trowler, 2001; Trowler \& Cooper, 2002). These TLR's have specific boundaries and disciplinary traditions, each potentially with its own traditions, its own specific notions of how things are done in the local context, its own codes of significance and discursive repertoires such as the ones described above (Trowler \& Cooper, 2002). This has implications for how change is enacted. If a top-down policy change is suggested, it may fall on deaf ears unless there is a sense of engagement from the faculty.

\section{CONTEXT AND RESPONDENTS}

The context of study is a medical university that has undergone significant educational reform during recent years, including the implementation of an outcome-based curriculum. The university is a research-intense life science and health care-oriented institution, which may have bearing on the types of TLRs present within the university and impacting the chances of change initiatives. Three respondents were purposefully chosen from the aforementioned group of 25 academics (collegial leaders) with the responsibility to communicate and coordinate matters related to undergraduate education in their respective departments. All three were engaged in research activity, had acted as program or course directors, had an expressed interest in educational matters, and had been allocated time to work in the collegial leader role. This collegial leader role was not a formal managerial role. However, they were called upon to act as change agents and were charged with the task of effecting change related to educational matters in their home department. Furthermore, their role was to act as a link between the university leadership and the teachers and administrative staff at their departments. They acted as conduits for the implementation of educational policies and change. The respondents that were interviewed were known to have initiated comprehensive changes within their local context, related to, among other things implementing new teaching and learning activities/methods of teaching, systematic collaborations between course directors, and development of assessment criteria. 


\section{METHODOLOGY, DATA COLLECTION, AND ANALYSIS}

A narrative approach was used to explore how change agents go about implementing change. Narrative inquiry captures in-depth understandings of a phenomenon and highlights the messiness and complexity of lived experience (McCance, McKenna, \& Boore, 2001; Greenhalgh, Russell, \& Swinglehurst, 2005; Jones, 2011). Narrative inquiry refers to a number of different research approaches (McCance et al., 2001; Nyman et al., 2012). Polkinghorne (1995) distinguishes between 1) analysis of narratives, whereby stories result in a categorisation of the experience of the respondents, and 2) narrative analysis, whereby data, events, and happenings are brought together to form a narrative. In this study we are concerned with the former, as we endeavoured to understand change implementation from the perspective of change agents. We used change agents' stories as an entry point to understand how they go about implementing and sustaining changes but also how their narratives relate to well-established CPP of how to manage change in organisations.

Each of the three respondents was interviewed on three different occasions in order to capture rich data. All interviews were transcribed verbatim. The first interview was open-ended, with the aim of understanding what kind of changes the respondents had experienced and initiated in relation to educational matters. We wished to investigate what changes they had initiated, what resistance they had faced, and how they had dealt with it. The second interview was structured around the changes they had brought about, eliciting more concrete examples of how they worked with change. The third interview was a group interview and was used as a member check, which is a form of informant or respondent feedback that improves the accuracy, credibility, and the validity of the findings (Creswell \& Miller, 2000). This made it possible to further deepen our understanding of how the prescriptions resonated with the change agents' experiences. During the third interview the Change Process Prescriptions were discussed with the respondents for the first time.

\section{Analysis step one}

Analysis of narratives involves an iterative process in which both inductive and deductive analysis can be used (Polkinghorne, 1988). The data was first analysed inductively to capture narratives of working with change, then a subsequent thematic analysis was conducted. In accordance with Braun and Clarke (2006), the transcripts were treated as follows:

1. They were read repeatedly to become familiar with the respondents and the way they addressed the topic.

2. Codes were identified by acknowledging events or significant happenings in the narratives/data. The coding was data-driven and not theory-driven, as this was the inductive phase of analysis.

3. Themes were identified from the coded material, seeing patterns that formed an overarching theme and avoiding overlap of themes.

4. Themes were defined and named. The essence of the theme was brought forward.

5. The themes were written up.

After the initial inductive analysis, themes were identified which captured the change agents' experiences of working with change.

\section{Analysis step two}

The second analysis involved approaching the data deductively, whereby the narratives of working with change were mapped into the Change Process Prescriptions as a form of pattern matching (Yin, 1984; Hyde, 2000). In pattern matching, a theory is expressed as a pattern of independent outcomes that are predicted to occur, in this case the Change Process Prescriptions. Support is then provided for the theory if the data matches the predicted pattern of outcomes more 
closely than predicted patterns for a counter theory (ibid). Finally, the themes were written up. The themes in the findings were reflected upon through the lenses of the CPP.

\section{LIMITATIONS}

The study explored the experiences of three respondents. This does not allow for broad generalisations; however, the aim was to gain deeper insights into how change agents experience change implementation and may help us understand how we can develop a more robust theory of change at the meso or departmental level. Consequently, it was necessary to generate rich data and return repeatedly to the respondents.

\section{FINDINGS}

The narratives represent change agents' ways of experiencing change implementation. The findings are presented as themes that illustrate the change agents' experience of change. Short vignettes are presented to illustrate the semantic meaning. It should be noted that the respondents could move between themes and may not be represented by every theme or one theme only. Four themes were identified:

- change as bargaining,

- change as identifying significant others,

- change as overcoming resistance, and

- change as overcoming territorial boundaries.

\section{Change as bargaining}

Change was seen as something initiated on several fronts, not only through formal decisionmaking processes, but also informal decision-making meetings. This involved complex networking, getting colleagues involved in change at different levels of the organisation. Building a basis for changes was deemed central. Respondents reported that change was often open to influence at an intermediate level. Informal networks were emphasised as very important as a way of understanding how the change would become manifest at departmental level.

So when decisions are made, many times when it comes up on the board then the administrators have a big impact. At the same time, the board of our university isn't very representative; the majority of those who sit on the board now represent the medical programme and there are maybe only one or two other professions, even though we are a very diverse university. So it is really important for me to get an idea of what is going on early and try and influence things through my broader network. I know people at all levels in the organisation, and when we meet in one context, for example over coffee or in conjunction with a conference, then I will discuss issues that are important for me, make my point clear, and will try to influence the decision-making process.

Change as bargaining offered the respondents a sense of ownership but it is a role that is played backstage where bargaining can sometimes require concessions of one form or another. The change agent who engages in a bargaining process is also exposed to counter-demands. The respondents talked about the importance of presenting changes to colleagues as salient and intelligent. The changes had to be put forward (Framed) as if there were clear benefits for students or teaching staff or the organisation. A new method of instruction or examination could be adopted even if this meant breaking with the old way of doing things as long as there were important outcomes, such as "better quality learning" or "retained understanding". In the instances when the participants were unclear 
about the positive effects of change they reported that there was a lack of clarity with regard to whom the changes would benefit. This was likely to put them off engaging with the proposed change. This could be seen in the themes concerned with overcoming resistance and also identifying significant others, as the respondents saw a need to work with people who could commit to change implementation. Bargaining involved defining and re-defining the frame for a planned initiative and was frequently talked about as something organic or as a "work in progress", something that had to be re-tried or re-defined based on the views of the participants, but also in light of the opportunities realised as a part of the intended change, again illuminating the notion of bargaining. The respondents reported that, without a genuine sense of shared importance, the likelihood of success was considerably diminished.

\section{Change as identifying significant others}

The participants reported that change implementation required identifying colleagues who were willing to share ideas and also develop ideas towards a common goal. This was possible, in particular when initiatives came from the bottom up and when the change implementation was related to issues of immediate relevance.

\section{I believe it's important to have a strong core-group that ensures that it is possible to implement the change (new curriculum), I think it is better that everyone isn't involved, just the key people. From there we need clear goals, these we kind of decide ourselves anyway, I mean I have tried to use my own goals a few times but that rarely works; then we have a long but interesting process of developing ideas, coming up with suggestions, meeting people, adapting ideas and so on. That way, everyone feels like it's been really transparent, so for sure the most important thing is probably the teachers, especially those with a vested interest. The others who are affected but not interested in changing things are the worst; they don't attend meetings, don't care, don't have an opinion and never have anything to say. These people I tend to give up on; maybe that's not a bad thing?}

Participation in change initiatives was at times a cause for concern as it involved overcoming resistance to change. Participants were mentioned in different ways; some participants were eager to have an impact. Participation as a significant other occurred either by accepting changes or by offering resistance to the changes, and this played an integral part in the framing and implementation of the change process. Other participants were at the periphery of the change process. This theme; Change as identifying significant others resonates with the theme Change as bargaining, but also overcoming resistance where the change agents had to engage significant others and bargain about participation, either by appealing to allegiances, common interests or even a shared history. The respondents stated that a pre-requisite for the change implementation to be successful was for the significant others to feel a sense of engagement. The respondents did not talk about participation as a concept; instead they evoked notions of getting people involved. In relation to change initiatives, significant others, one could argue are represented along the entire HE occupational continuum, from administrative staff, to teachers, to fellow collegial leaders, heads of departments etc. However, the respondents differed in relation to which type of people they would identify; some would turn to their closest colleagues only, whereas others acknowledged the importance of engaging administrative staff as well. Generally, external expertise, such as academic development, was not called for. Recruiting others or outsiders such as academic developers was, to a rather large degree, reduced to a question of money. When available, the respondents reported, then it was a good idea 
to use external resources in the form of educational developers, but often, and especially in relation to less radical changes, the change process was led from within the local community.

\section{Change as overcoming resistance}

In this theme, resistance to change was reported from a number of directions. In part it was characterised by an asymmetrical relationship to management who did not engage in discussions about impending changes, or did not give feedback on suggestions for changes. At times, upper management would decide on policy changes but would not follow up on implementation, leaving the change agents isolated. There was also resistance from colleagues; this could take the form of non-change, when nothing was done to enforce the top-down change, or by actively resisting in the form of calling into question the change implementation. On occasion, this evoked pragmatic compliance, whereby implementers adjusted the intended change to suit the local context but where there was no dialogue vis-a-vis the intended change. A consequence of this was that many campuswide changes had one original idea but several actual manifestations. The respondents reported that they wished for more understanding from upper management, but also from colleagues regarding how difficult change implementation could be time- and resourcedemanding, suggesting that the change agents were rather stuck between resistance from above and below. The lack of feedback was a cause for concern in relation to top-down changes, particularly as the respondents reported that these were generally less likely to have a widespread impact.

Well I mean we deal with a lot of changes that we have not really chosen ourselves. People don't really see the point of changing things, and when they do we never really get feedback if we have ideas on, let's say the original proposal. That is really a tough one, I mean getting people to commit when there is no dialogue. I don't think the university as an organisation understands really how hard it is to figure out what is meant by a particular change... I mean we often send them feedback but we never hear anything back from them ... it's like they just don't listen. I point this out but nothing happens... but sure, in the end we get the job or we get a job done anyway, I mean we have a good girls syndrome right, and we make sure the job gets done.

When recruiting within the organisation, the respondents mentioned "the same old gang" and were weary of crossing lines and engaging others in the change implementation. This resonated with the next theme, change as overcoming territorial boundaries, in the sense that recruiting for educational change involved recruiting staff whose primary task was perhaps research or clinical work, and as such there was a territorial boundary in relation to education. The respondents argued that this had implications for how things were conducted; who led the meetings, which discipline was given prominence in different projects etc. The respondents also highlighted academia's sense of honour in that in academia people make sure to get things done, because "we owe it to the students". There was also a sense that people within academia knew what to do when it came to education, expressed as a "foolhardy belief in one's own ability". The respondents argued they would get the job done, regardless of the costs, and that this meant putting in extra hours, formulating the outcomes, planning the change process etc.

\section{Change as overcoming territorial boundaries}

A challenge that was reported was related to long-standing departmental and disciplinarian traditions. The competitive and tribal nature of academic disciplines made 
change implementation particularly difficult. At the current university, collegial leaders often had multiple roles; as teachers, researchers and clinicians, and could be involved in a number of different contexts. It was not uncommon that the traditions that were borne out of territorial boundaries would prevent change happening, in part because people had allegiances with different territories, but also because each of these territories had firmly set ways of doing certain things, such as teaching, rounds and/or examinations.

It's really funny, I mean this place is so, mm ... tribal, it's not like anyone is going to step up and say, 'Hey my discipline isn't so important, we can take it away', so it's really important that we can do some bargaining, a little bit of this, a little bit of that, moving towards our goal, which is better student learning through integrated knowledge. Still we end up a long way from the original [the proposed] idea. Sometimes I think the easiest thing would be to scrap it all and start from scratch ... I mean we are so imbued with tradition here that any change takes ages, small steps forward. It is just the nature of things here, I guess.

Territorial boundaries could be viewed from a number of perspectives. The traditional teaching-research nexus was one such perspective. Another, more contextspecific perspective was the medical education context. At this particular medical university there was an implied natural order of things whereby the medical programme had the most weight to throw around.

The four themes above represent the narratives of change and offer an idea of the types of tensions, frustration and messiness involved in the process of change. The themes represent a patterned response or meaning within the data set, in this case the types of tensions the change agents encountered, but also the strategies they adopted to overcome these obstacles (Braun \& Clarke, 2006). The second part of the study set about mapping the change agents' stories of change implementation with the Change Process Prescriptions (Meyer \& Stensaker, 2006), and these were mapped into the themes when possible.

\section{DISCUSSION}

Our aim was to deepen knowledge about how change agents experience change implementation. In doing so, we have aimed to answer two research questions. Firstly, how do change agents go about implementing change? Secondly, how can we understand tensions between these change agents' experiences of change and systematic models of change? Question one was approached by eliciting stories of change from change agents, and question two was approached by analysing and mapping the stories of change into the change prescriptions; framing, participation, pacing and sequencing, routinizing and recruiting (Meyer \& Stensaker, 2006). The findings show how change agents in higher education initiated change, how they described the types of resistance they encountered along the way, and also how they acted when they met resistance. The findings suggest that serendipity plays a part in change implementation, and also that the change agents seldom have a long-term plan for implementing change or a systematic approach to change implementation. This may, in part, be related to the fact that they have no formal training in driving change.

The analysis suggests a partial overlap between the narratives of change implementation and the CPP (Meyer \& Stensaker, 2006); in other words, we could see how framing, participation and recruiting were implicitly part of the change agents' experiences, although they were talked about in non-theoretical terms. However, we could also identify aspects of the CPP that were absent in the stories of change, such as pacing and sequencing, and routinizing, which are commented upon here. 


\section{Pacing and Sequencing}

The respondents reported that change does not occur overnight and expressed concern that top management has little understanding of what it means to implement broad-based changes. Instead, change occurs incrementally; if a new method of teaching was to be introduced then it involved careful adjustment and revision. At the same time, the respondents also said that it would be much easier just to start afresh. Time is an essential aspect of the change process. Even radical changes take time, especially if genuine change is to be achieved. Pacing \& sequencing was missing in the respondents' narratives of change. Instead, they talked about getting things done, which suggests a sense of urgency and being in the present, doing things. When the notion of pacing and sequencing was brought up, the respondents talked about change as something organic, as something that took time, but there was little evidence for how pacing and sequencing were considered and addressed as part of a systematic approach to change implementation.

\section{Routinizing}

Generally, the respondents did not consider routinizing, even though change was seen as a norm. This came as somewhat of a surprise for the research team, given the challenges described in the literature in relation to sustaining daily operation and managing change. According to the respondents, change in $\mathrm{HE}$ is part and parcel of the way a university operates. The respondents mentioned how "nothing stands still," for example when dealing with students there is always a need to develop; tweaking the way things are done to improve them. The respondents evoked the idea of working at a research institute, where there was a momentum towards development and change. In line with the literature we identify at least two types of change: 1) a disposition towards change and one's own work practice, and 2) the idea that the organisation itself needs to develop the habit of implementing changes (Meyer \& Stensaker, 2006; Tsoukas \& Chia, 2002). It was clear that the respondents felt that they had achieved the former but did not really consider the latter, nor did they have a strategy for how the change mentality of their organisation could be made operational and how routinizing could be brought into play. This needs to be seen in light of the three interconnected capabilities addressed earlier:

a) the capability to maintain daily operations,

b) the capability to implement a single change, and

c) the capability to implement subsequent changes (Meyer \& Stensaker, 2006).

Change in this study was characterised as being brought about in a pragmatic, non-systematic, almost naïve fashion. At times it involved bargaining and complex networking, at times identifying significant others to collaborate with, at times it involved overcoming resistance or inertia, and at other times it involved overcoming territorial boundaries. The respondents reported that change did not happen in a vacuum, instead it occurred and was dependent on others' engagement; repeated negotiations had to take place in order for change to happen. This is acknowledged and articulated throughout the literature (Tsoukas \& Chia 2002; Trowler \& Cooper, 2002; Trowler et al., 2005; Meyer \& Stensaker, 2006) as being part of a participation process; however, the significance of resistance and negotiation is further emphasised in this article. Resistance and negotiation were highlighted in particular when the respondents talked about how they experienced change implementation. The respondents acknowledged that the idea of change prescriptions was appealing, intuitively, but felt that such a framework did not really capture the complexity of working with change implementation, while, at the same time the respondents did not have a conscious or systematic approach to change implementation. They reported that people were, sometimes, stuck in old ways of doing things and at times were unlikely to participate in change implementation. They also reported that colleagues could, at first, say that they could take part in changes only to neglect taking responsibility later on in the process. It was evident that resistance requires negotiation, but 
equally clear that change agents may need a framework in order to work systematically with change agency. Trowler argues that change agents need to engage in careful analysis of content (innovation), context and the interactions between them, and further stresses the importance of change agents being informed both conceptually and theoretically about change (Trowler, 2008). As mentioned previously, Caldwell (2006) identifies four agency discourses: the rationalist, the contextualist, the dispersalist and the constructionist. The resistance our change agents gave voice to could also, to some degree, be explained by the fact that their colleagues, both in upper management and their most immediate colleagues, embodied different discourses. However, in our study it was evident that the change agents did not have conceptual or theoretical ideas about change agency, nor did they express any awareness of the different discourses operating during the change process. In this study we could see that the change agents had naïve conceptual and theoretical understanding. Change agents in higher education may have to take into consideration the special nature of each context, each TLR, meaning that change agents need to identify general principles of change agency while simultaneously acknowledging the importance of the local context (Trowler, 2008; Brown et al., 2012). As such, the CPP or other systematic approaches could act as heuristic tools for change agents to reflect upon when implementing change.

Our findings suggest two notions to pursue further:

a) change agents are negotiators of change and will always encounter resistance, which is both an obstacle but also a catalyst for change

b) change agents lack a systematic approach to change agency

In this study we could see that negotiation took place in different ways; sometimes it involved negotiating the planned change, whereas at other times it involved negotiating the process of change. This is in line with previous research which suggests that significant networks may be important for driving change (Roxå \& Mårtensson, 2009). However, it was also evident that the change agents lacked a strategic and systematic approach to implementing change. This is a challenge given that broad department-wide change requires dialogue between different types of stakeholders, which also involves, at times, transgressing territorial boundaries (Becher \& Trowler, 2001). Dialogue needs to be moderated both up-front and in the open, but also backstage on a more informal basis. When change happens, there is and needs to be negotiation regarding how change becomes operational. The change agents' role here is one of a negotiator or broker, because change is congruent on the participation of colleagues and peers and so negotiation must take place for change to happen. In line with the literature (Tsoukas \& Chia, 2002; Trowler \& Cooper, 2002; Trowler et al., 2005; Meyer \& Stensaker, 2006) we acknowledge that participation is a necessary feature of any instance of change but based on our findings we would emphasise even further the importance of resistance and negotiation in change implementation in order to bring about a mutual and meaningful compliance. It seems plausible that resistance to change may be necessary for learning and change to occur and that resistance is perhaps catalytic in the change processes (Ford et al., 2008). Given that change occurs in a social setting, it may be necessary for change to take place as part of collective sensemaking. Our previous work acknowledges that academic developers, together with people in a leadership capacity at both departmental and university-wide levels need to consider different ways of creating opportunities for peer dialogue on educational issues in order to fully embrace opportunities for change (McGrath \& Bolander Laksov, 2014). This resonates with the notion of change agents as brokers and negotiators within their local communities (Bolander Laksov et al., 2008). Change implementation is an on-going process of negotiation and modification of ideas, where the desired change is reified locally, framed locally, enacted locally and thus becomes enacted change. For genuine change to happen then the change agents may benefit from acknowledging resistance and negotiating with participants about framing, participation and pacing etc. 
The other notion we wished to emphasise here is that change agents seemed to lack a systematic approach to change agency. Essentially, they had intuitive and pragmatic approaches but they were not conscious or systematic approaches to change. At the beginning of the text we addressed the idea that higher education institutions embrace collegial cultures towards leadership as opposed to a managerial culture (Berquist, 1992). At the meso level, change is often initiated by staff who are experts in their fields but amateurs in relation to change management and agency (Askling \& Stensaker, 2002). However, and perhaps equally as important, change agents need to consider how an organisation deals with calls for multiple changes (Askling \& Stensaker, 2002; Trowler, 2008). In doing so, the change agents can identify resistance and negotiation as part of a process of scrutinising ideas, and this allows them to recognize opportunities for negotiation. However, for this to happen, change agents may need training in how to deal with change implementation. This could be done through training in understanding change and organisation discourses, training in using conceptual frameworks such as the CPP as heuristic tools for analysing on-going change implementation, or by coming to understand the process of change and developing an understanding of how to deal with resistance. Whatever approach is way, our findings suggest that collegial leaders need help in developing conceptual and theoretical understanding of change (Trowler, 2013).

\section{CONCLUSION}

In this paper we explored how change agents experience change implementation in higher education. Our findings are in line with previous research and suggest that a university's change capacity may be reliant, in part, on change agents' ability to identify and understand the complexity of change implementation. Furthermore, this study offers some insight into the tension that exists between how individuals go about change implementation, emphasising how Change Process Prescriptions may offer support for how change could be organised. Furthermore, it highlights the fact that change agents in universities seldom have a systematic approach to change agency. The findings may offer pedagogical leaders and academic developers alike an insight into the complex nature of the change process, and could also inform change agents as to the importance of their role and provide a view of resistance and negotiation as natural parts of the change process. Future studies could involve action research and longitudinal studies whereby change agents are offered guidance in negotiating change and building capacity, for example by using conceptual frameworks such as Meyer and Stensaker's (2006) Change Process Prescriptions. In this way, such studies could inform an emerging theory of change agency in higher education.

\section{ACKNOWLEDGMENTS}

The authors are grateful to the anonymous reviewers for their critical and insightful comments on earlier versions of this paper.

Cormac McGrath is assistant lecturer and researcher at the Karolinska Institutet.

Linda Barman is a university teacher and educational developer at the School of Communication and Learning in Engineering Science at the Royal Institute of Technology in Stockholm, Sweden.

Terese Stenfors-Hayes is Director of the Unit for Evaluation at the department of Learning, Informatics, Management, and Ethics at Karolinska Institutet, Sweden.

Torgny Roxå serves as academic developer at the Faculty of Engineering at Lund University in Sweden since 1988. His focus is Strategic Educational Development using a socio-cultural approach. 
Charlotte Silén is an associate professor in Medical Education and director of a Master's programme in Medical Education with experience in faculty and educational development within higher education.

Klara Bolander Laksov is an associate professor and director of the Centre for Teaching and Learning at the department of Education at Stockholm University, and associate professor at the department of Learning, Informatics, Management, and Ethics at Karolinska Institutet, Sweden.

NOTE

1. Charlotte Silén and Klara Bolander Laksov have contributed equally.

\section{REFERENCES}

Amis, J., Slack, T., \& Hinings, C. R. (2004). The pace, sequence, and linearity of radical change. Academy of Management Journal, 47(1), 15-39.

Askling, B., \& Stensaker, B. (2002). Academic leadership: Prescriptions, practices and paradoxes. Tertiary Education and Management, 8(2), 113-125. doi: 10.1023/a:1015612510179

Barman, L., Silén, C., \& Bolander Laksov, K., Outcome based education enacted: teachers' tensions in balancing between student learning and bureaucracy. Advances in Health Sciences Education 19.5 (2014): 629-643.

Barman, L., Bolander-Laksov, K., \& Silén C. Policy enacted-teachers' approaches to an outcome-based framework for course design. Teaching in Higher Education 19.7 (2014): 735-746.

Becher, T., \& Trowler, P. (2001). Academic tribes and territories: intellectual enquiry and the culture of disciplines (2nd ed.). Philadelphia, PA: Open University Press.

Bergquist, W. (1992). The four cultures of the academy. San Francisco: Jossey Bass.

Bolander Laksov, K., Mann, S., \& Dahlgren, L. O. (2008). Developing a community of practice around teaching: A case study. Higher Education Research \& Development, 27(2), 121-132.

Bolander Laksov, K, \& Tomson, T. "Becoming an educational leader-exploring leadership in medical education." International Journal of Leadership in Education (2016): 1-11.

Bolden, R., Petrov, G., \& Gosling, J. (2009). Distributed leadership in higher education rhetoric and reality. Educational Management Administration \& Leadership, 37(2), 257-277. Doi: $10.1177 / 1741143208100301$

Braun, V., \& Clarke, V. (2006). Using thematic analysis in psychology. Qualitative Research in Psychology, 3(2), 77-101. doi: 10.1191/1478088706qp063oa

Caldwell, R. (2006). Agency and change: Rethinking change agency in organizations. London; New York: Routledge.

Creswell, J. W., \& Miller, D. L. (2000). Determining validity in qualitative inquiry. Theory into Practice, 39(3), 124-130. doi: 10.1207/S15430421tip3903_2

Dover, P. (2002). Change agents at work: Lessons from Siemens Nixdorf. Journal of Change Management, 3(3), 243-257. doi: $10.1080 / 714042535$

Ford, J. D., Ford, L. W., \& D'Amelio, A. (2008). Resistance to change: The rest of the story. Academy of Management Review, 33(2), 362-377.

Greenhalgh, T., Russell, J., \& Swinglehurst, D. (2005). Narrative methods in quality improvement research. Quality \& Safety in Health Care, 14(6), 443-449. doi: 10.1136/Qshc.2005.014712

Higgs, M., \& Rowland, D. (2000). Building change leadership capability: 'The quest for change competence.' Journal of Change Management, 1(2), 116-130. doi: 10.1080/714042459

Hyde, K. (2000). Recognising deductive processes in qualitative research. Qualitative Market Research: An International Journal. 3(2), 82-90.

Jones, A. (2011). Seeing the messiness of academic practice: Exploring the work of academics through narrative. International Journal for Academic Development, 16(2), 109-118. doi: $10.1080 / 1360144 X .2011 .568282$

McCance, T. V., McKenna, H. P., \& Boore, J. R. P. (2001) Exploring caring using narrative methodology: An analysis of the approach. Journal of Advanced Nursing 33(3), 350-356.

McGrath, C., \& Bolander Laksov, K. (2014). Laying bare educational crosstalk: A study of discursive repertoires in the wake of educational reform. International Journal for Academic Development, 1-11. doi: $10.1080 / 1360144 \times .2012 .716760$

Meyer, C. B., \& Stensaker, I. G. (2006). Developing capacity for change. Journal of Change Management, 6(2), 217-231. doi: 10.1080/14697010600693731 
Newton, J. (2003). Implementing an institution-wide learning and teaching strategy: lessons in managing change. Studies in Higher Education, 28(4), 427-441. doi: 10.1080/0307507032000122279

Nyman, A., Josephsson, S., \& Isaksson, G., (2012) Being part of an enacted togetherness: Narratives of elderly people with depression. Journal of Aging Studies (26) 4.

Polkinghorne, D. (1988). Narrative knowing and the human sciences. Albany: State University of New York Press.

Polkinghorne, D. E. (1995). Narrative configuration in qualitative analysis. International Journal of Qualitative Studies in Education, 8(1), 5-23. doi: 10.1080/0951839950080103

Polkinghorne, D. E. (2007). Validity issues in narrative research. Qualitative Inquiry, 13(4), 471-486. doi:10.1177/1077800406297670

Roxå, T., \& Mårtensson, K. (2009). Significant conversations and significant networks-Exploring the backstage of the teaching arena. Studies in Higher Education (34) doi:10.1080/03075070802597200

Stensaker, B. (1999) In charge? (Absent) academic leadership during external assessments. International Journal of Educational Management, (13) 6, 266-272

Trowler, P., \& Cooper, A. (2002). Teaching and learning regimes: Implicit theories and recurrent practices in the enhancement of teaching and learning through educational development programmes. Higher Education Research \& Development, 21(3), 221-240. doi: 10.1080/0729436022000020742

Trowler, P., Fanghanel, J., \& Wareham, T. (2005). Freeing the chi of change: The Higher Education Academy and enhancing teaching and learning in higher education. Studies in Higher Education, 30(4), 427444. doi: 10.1080/03075070500160111

Trowler, P. (2008). Cultures and change in higher education: Theories and practices. Houndmills, Basingstoke, Hampshire; New York: Palgrave Macmillan.

Trowler, P., Hopkinson, P., \& Comerford Boyes, L. (2013). Institutional change towards a sustainability agenda: How far can theory assist? Tertiary Education and Management, 19(3), 267-279. doi: $10.1080 / 13583883.2013 .798349$

Tsoukas, H., \& Chia, R. (2002). On organizational becoming: Rethinking organizational change. Organization Science, 13(5), 567-582. doi: 10.1287/orsc.13.5.567.7810

Yin, R. K. (1984), Case study research: Design and methods. Thousand Oaks, CA: Sage.

Copyright for the content of articles published in Teaching \& Learning Inquiry resides with the authors, and copyright for the publication layout resides with the journal. These copyright holders have agreed that this article should be available on open access under a Creative Commons Attribution License 4.0 International (https://creativecommons.org/licenses/by/4.0). The only constraint on reproduction and distribution, and the only role for copyright in this domain, should be to give authors control over the integrity of their work and the right to be properly acknowledged and cited, and to cite Teaching \& Learning Inquiry as the original place of publication. Readers are free to share these materials-as long as appropriate credit is given, a link to the license is provided, and any changes are indicated. 